\title{
Physical Activity Levels among Children Attending After-School Programs
}

\author{
STEWART G. TROST ${ }^{1}$, RICHARD R. ROSENKRANZ ${ }^{2}$, and DAVID DZEWALTOWSKI ${ }^{2}$ \\ ${ }^{I}$ Department of Nutrition and Exercise Sciences, Oregon State University, Corvallis, OR; \\ and ${ }^{2}$ Department of Kinesiology, Kansas State University, Manhattan, KS
}

\begin{abstract}
TROST, S. G., R. R. ROSENKRANZ, and D. DZEWALTOWSKI. Physical Activity Levels among Children Attending After-School Programs. Med. Sci. Sports Exerc., Vol. 40, No. 4, pp. 622-629, 2008. Purpose: To describe the physical activity (PA) levels of children attending after-school programs, 2) examine PA levels in specific after-school sessions and activity contexts, and 3) evaluate after-school PA differences in groups defined by sex and weight status. Methods: One hundred forty-seven students in grades 3-6 (mean age: $10.1 \pm$ $0.7,54.4 \%$ male, $16.5 \%$ overweight (OW), $22.8 \%$ at-risk for OW) from seven after-school programs in the midwestern United States wore Actigraph GT1M accelerometers for the duration of their attendance to the program. PA was objectively assessed on six occasions during an academic year (three fall and three spring). Stored activity counts were uploaded to a customized data-reduction program to determine minutes of sedentary (SED), light (LPA), moderate (MPA), vigorous (VPA), and moderate-to-vigorous (MVPA) physical activity. Time spent in each intensity category was calculated for the duration of program attendance, as well as specific after-school sessions (e.g., free play, snack time). Results: On average, participants exhibited 42.6 min of SED, 40.8 min of LPA, 13.4 min of MPA, and $5.3 \mathrm{~min}$ of VPA. The average accumulation of MVPA was $20.3 \mathrm{~min}$. Boys exhibited higher levels of MPA, VPA, and MVPA, and lower levels of SED and LPA, than girls. OW and at-risk-for-OW students exhibited significantly less VPA than nonoverweight students, but similar levels of LPA, MPA, and MVPA. MVPA levels were significantly higher during free-play activity sessions than during organized or structured activity sessions. Conclusion: After-school programs seem to be an important contributor to the PA of attending children. Nevertheless, ample room for improvement exists by making better use of existing time devoted to physical activity.
\end{abstract} Key Words: YOUTH, MOTION SENSORS, ACCELEROMETER, EXERCISE, OUT-OF-SCHOOL TIME

$\mathrm{D}$ uring the last three decades, the prevalence of overweight has more than tripled among U.S. children and adolescents. According to the most recent National Health and Nutrition Examination Survey (NHANES 2003-2004), just more than 17\% of children and adolescents aged $2-19$ yr are overweight, with an additional $16.5 \%$ considered at risk for overweight (19). The dramatic rise in childhood overweight has been deemed one of the most serious public health issues facing society today $(9,19)$. Overweight youth are at increased risk for adult obesity (39), and, compared with their nonoverweight

\footnotetext{
Address for correspondence: Stewart Trost, Ph.D., Department of Nutrition and Exercise Sciences, 203D Women's Building, Oregon State University, Corvallis, OR 97333; E-mail: stewart.trost@oregonstate.edu.

Submitted for publication May 2007.

Accepted for publication November 2007.

0195-9131/08/4004-0622/0

MEDICINE \& SCIENCE IN SPORTS \& EXERCISE E $_{\circledast}$ Copyright $\odot 2008$ by the American College of Sports Medicine

DOI: 10.1249/MSS.0b013e318161 eaa5
}

counterparts, they are at increased risk for significant short-term health problems such as insulin resistance, hypertension, respiratory problems, and orthopedic complications (8). Moreover, the adverse social consequences of childhood overweight may have long-lasting negative effects on self-esteem and other indicators of psychological well-being (8).

Regular physical activity plays a critical role in the primary and secondary prevention of overweight (28). Yet, despite its importance, a large percentage of U.S. children and adolescents do not meet established guidelines for participation in physical activity. Currently, only $36 \%$ of high school students report participating in $60 \mathrm{~min}$ of moderateto-vigorous physical activity (MVPA) on five or more days of the week (5). Among children aged 9-13 yr, nearly $62 \%$ report no participation in organized physical activity outside of school, with approximately $23 \%$ reporting no participation in organized MVPA during their free time (4). In a study using accelerometry to quantify physical activity in a population-based sample of school children, the percentage of children meeting the 60-min MVPA recommendation declined from $100 \%$ in students from grades $1-3,89.7 \%$ in 
students from grades $4-6,58.3 \%$ in students from grades $7-$ 9 , to $29.4 \%$ in students from grades $10-12$ (21). These findings underscore the need for widespread efforts to promote regular physical activity in youth.

Schools are an ideal setting to promote physical activity because they 1) reach most children and adolescents, 2) have trained personnel with an interest in promoting health, 3) have an organization structure and facilities that can be used to promote physical activity, and 4) have a capacity to interact with community-based physical activity providers and other community groups (23). However, with schools facing increasing pressure to improve standardized test scores in reading and math, opportunities for physical activity instruction and programs during the school day have declined considerably (18). Data from the 2000 School Health Policies and Program Study (SHPPS) indicate that only $8 \%$ of elementary schools, $6.4 \%$ of middle schools, and $5.8 \%$ of senior high schools provide daily physical education or its equivalent for the entire school year (2). Additionally, many schools have significantly reduced the time allocated to recess, with some school districts eliminating recess completely (23).

In response to these trends, researchers and interventionists have begun to focus on opportunities to promote physical activity during the after-school time period, especially through after-school programs. Importantly, after-school programs have the capacity and infrastructure to reach large numbers of children and adolescents. According to an unpublished survey by the After-School Alliance, there are currently 6.5 million children attending after-school programs in the United States, and this number is likely to grow because of 1) shifting family demographics such as higher numbers of single and employed mothers, 2) the increased attention to academic performance and prevention of problem behaviors in schools, and 3) an intensified focus on positive youth development (37).

After-school programs have the potential to promote physical activity by providing structured and unstructured opportunities for physical activity and teaching students behavioral and movement skills associated with lifelong participation in physical activity. However, the available literature shows after-school programs to be quite heterogeneous with regard to the children being served, the types of activities offered, and the training and background of the staff (37). Although a small number of investigations have quantified physical activity levels during the after-school time period $(6,7,10,36)$, none have considered the location or context of physical activity or specifically evaluated the physical activity levels of children attending formal afterschool programs. Consequently, we know very little about the activity levels of children attending after-school programs. Importantly, knowledge of the quantity and quality of the physical activity provided by after-school programs, and the factors that influence activity behavior in this setting (sex, weight status), will enable education and public health officials to make more informed decisions about policies and practices related to promoting physical activity and preventing obesity in the after-school time period. Therefore, the aims of this study were threefold: 1 ) describe the physical activity levels of children attending afterschool programs, 2) examine physical activity levels in specific after-school sessions and activity contexts, and 3) evaluate sex and weight-status differences in after-school physical activity. We evaluated sex differences in afterschool program activity because previous objective monitoring studies have noted differences in other important school settings such as school physical education class and recess $(25,26)$.

\section{METHODS}

\section{Participants and Setting}

Participants for this study were recruited from seven after-school programs operating in a single school district in the midwestern United States. All seven after-school programs were part of a local After-School Alliance, supported by user fees and grant funding from the United Way (http://national.unitedway.org) and the 21st Century Community Learning Centers Program (http://www.ed.gov/ programs/21stcclc/index.html). Each site was staffed with a full-time program manager and several part-time group leaders who directly supervised the children. Program managers were required to have an associate degree or more than $2 \mathrm{yr}$ of college and $3 \mathrm{yr}$ of experience as a group leader. Group leaders were required to have some college (or pass a qualification test) and previous experience working with after-school programs. Notably, program leaders did not have any specialized training in physical education or physical activity programming. All programs offered core components including daily "power hour" academic time, snack, and recreational opportunities. The average group leader:student ratio was 1:6. Each site began the program day immediately after school ended. Four of the programs began at 3:00 p.m. and ended at 5:30 p.m., and three programs ran from 3:45 p.m. to 6:00 p.m. Parents were allowed to pick up children at any time, and some sites allowed children to sign themselves out earlier than the scheduled end time.

Enrollment in the seven schools hosting the programs ranged from 194 to 477 (mean $=309)$, and the proportion of minority students ranged from 9 to $51 \%$ (mean $=31.2 \%$ ). The sample of schools was also economically diverse, with the percentage of students eligible for free or reduced lunch ranging from 6 to $73 \%($ mean $=43 \%)$. From the seven schools, 170 after-school program participants in grades 3 through 6 were eligible to participate in the study. Of this number, $147(86.5 \%)$ elected to participate in the study by returning the required parental consent and student assent documents. The study was approved by the Kansas State University institutional review board and the school district's research committee. 


\section{Assessment of Physical Activity}

Instrumentation. Objective assessments of physical activity were obtained using the ActiGraph GT1M accelerometer (Shalimar, FL). The ActiGraph is a small $(3.8 \times 3.7 \times 1.8 \mathrm{~cm})$, lightweight $(27 \mathrm{~g})$ accelerometer designed to detect vertical accelerations ranging in magnitude from 0.05 to $2.00 \mathrm{~g}$, with a frequency response of $0.25-2.50 \mathrm{~Hz}$. These parameters allow for the detection of normal human motion and will reject high-frequency vibrations encountered during activities such as operation of a lawnmower. The acceleration signal is digitized at a rate of $30 \mathrm{~Hz}$ and filtered, rectified, and integrated through a user-specified interval called an epoch. At the end of each epoch, the summed value or "activity count" is stored in memory, and the integrator is reset. Because the 1-min epoch typically used for accelerometry may mask the intermittent activity patterns of children (32), a 30-s epoch was used. The ActiGraph is the most widely used accelerometer in pediatric research $(11,32)$ and has been shown to be a valid and reliable tool for quantifying physical activity in children and adolescents (35).

Protocol. Objective monitoring at each after-school program site was performed on six occasions during the course of the academic year, with three monitoring waves completed during the fall semester and three completed during the spring semester. Students wore the accelerometer for the duration of their attendance at the after-school program. At the beginning of the program, a research assistant attached an ActiGraph accelerometer to each student's right hip via an adjustable elastic belt, noting the time of attachment, the identification number of the student, and the identification number of the accelerometer. At the completion of the after-school program, or as the student was leaving the program (whichever came first), the research assistant removed the accelerometer and noted the time of departure. Accelerometers were subsequently transported back to the laboratory for data downloading and storage.

On each monitoring day, a research assistant recorded the different session types that occurred during the after-school program in a customized log book, noting the start and stop time of each session. The coding scheme was based on the SOPLAY observational system developed by McKenzie and colleagues (17). Sessions were coded as follows: 1) unsupervised free play indoors, 2) supervised free play indoors, 3) organized activity indoors, 4) unsupervised free play outdoors, 5) supervised free play outdoors, 6) organized activity outdoors, 7) snack time, or 8) academic time. Sessions were coded as supervised if after-school program personnel were in or adjacent to the area (i.e., available to direct students and respond to emergencies). Sessions were coded as organized if after-school program personnel instructed, coached, officiated, or co-coordinated the activity session in any way. Sessions not meeting the definition of organized were coded as free play and resembled recess.

\section{Data Reduction}

Raw accelerometer counts were uploaded to a customized software program for determination of time spent in sedentary (SED; < 1.5 METs), light (LPA; 1.5-3.9 METs), moderate (MPA; 4-6.9 METs), vigorous (VPA; $\geq 7$ METs), and moderate-to-vigorous (MVPA; $\geq 4$ METs) physical activity. The age-specific count thresholds corresponding to these intensity levels were derived from the MET prediction equation developed by Freedson and coworkers (11) and mirrored the intensity categories used in other recently published objective monitoring studies $(22,27,40)$. To accommodate the 30-s epoch length, the appropriate agespecific count thresholds were divided by two. The datareduction program computed the physical activity variables for the duration of program attendance, as well as for specific after-school sessions on that day. To accomplish this task, the session codes (described above) and their respective start and stop times were entered into the software program, along with the start and stop times for the student's attendance throughout the entire program. If the student left the after-school program before the start of a session, the session code and respective session times were set to missing. Nonwearing time for the entire after-school period and each session type was assessed by summing the number of consecutive zero counts accumulated in strings of $10 \mathrm{~min}$ or longer. Accelerometer data for the entire afterschool period was considered valid if wearing time (program duration minus total minutes of consecutive zero counts) was equal to or greater than $60 \mathrm{~min}$. For each afterschool session type, accelerometer data were considered valid if wearing time (session duration minus minutes of consecutive zero counts for the session) was equal to or greater than $15 \mathrm{~min}$.

\section{Anthropometric Measures and Weight Status}

Height and weight assessments were conducted in a private setting with students dressed in light clothing and shoes removed. Height was measured to the nearest $0.1 \mathrm{~cm}$,

\begin{tabular}{lc} 
TABLE 1. Descriptive characteristics of the after-school program participants $(N=140)$ \\
\hline Age (yr) & $10.1 \pm 0.7$ \\
Gender (\%) & 56.4 \\
Male & 43.6 \\
Female & \\
Ethnicity (\%) & 48.6 \\
White & 17.9 \\
African American & 10.7 \\
Hispanic & 7.1 \\
Native American & 0.7 \\
Asian & 15.0 \\
Not reported & \\
Reduced or free lunch (\%) & 34.2 \\
Yes & 38.6 \\
No & 27.2 \\
Not reported & \\
Weight status (\%) & 16.5 \\
Overweight & 22.8 \\
At-risk overweight & 60.7 \\
Nonoverweight &
\end{tabular}




\begin{tabular}{|c|c|c|c|c|c|}
\hline \multirow[b]{2}{*}{ Group } & \multicolumn{5}{|c|}{ Physical Activity (min) } \\
\hline & Sedentary & Light & Moderate & Vigorous\# & MVPA \\
\hline Total sample & $42.6 \pm 0.6$ & $40.8 \pm 0.6$ & $13.4 \pm 0.4$ & $5.3 \pm 0.3$ & $20.3 \pm 0.8$ \\
\hline Boys & $42.4 \pm 1.2$ & $37.7 \pm 0.8^{\star}$ & $14.8 \pm 0.5$ & $6.8 \pm 0.6^{\star}$ & $23.7 \pm 1.0^{*}$ \\
\hline Girls & $42.8 \pm 1.3$ & $43.8 \pm 0.8$ & $12.1 \pm 0.6$ & $4.1 \pm 0.4$ & $17.3 \pm 1.1$ \\
\hline Nonoverweight & $41.7 \pm 1.1$ & $40.5 \pm 0.7$ & $13.4 \pm 0.5$ & $6.0 \pm 0.5 \ddagger$ & $21.5 \pm 0.9$ \\
\hline Overweight & $43.5 \pm 1.4$ & $40.9 \pm 0.9$ & $13.4 \pm 0.6$ & $4.6 \pm 0.5$ & $19.3 \pm 1.2$ \\
\hline
\end{tabular}

\# Adjusted means for vigorous physical activity derived from a generalized linear mixed model using Poisson distribution and log link function.

* Boys significantly different from girls, $P<0.05$

‡ Nonoverweight significantly different from overweight, $P<0.05$.

using a portable stadiometer (Invicta Plastics Ltd, Leicester, $\mathrm{UK}$ ). Weight was measured to the nearest $0.1 \mathrm{~kg}$ with highprecision electronic scales (Seca Corp, Model 770, Hamburg, Germany). Body mass index (BMI) was calculated as body weight divided by height squared $\left(\mathrm{kg} \cdot \mathrm{m}^{-2}\right)$. BMI scores were converted to percentiles using the age- and sexspecific LMS parameters from the CDC growth charts. Participants were classified as overweight or at risk for overweight, respectively, if their BMI equaled or exceeded the age- and sex-specific 95th or 85th percentile (15).

\section{Statistical Analyses}

All statistical analyses were performed using SAS software (version 9.1; SAS Institute, Cary, NC). Differences in the physical activity variables, with the exception of vigorous physical activity, were evaluated for significance using a general linear mixed model and PROC MIXED. For physical activity levels during the entire after-school period, the model included measurement wave, gender, and weight status as fixed effects; students nested within after-school program as a random effect (to address clustering of students within program); with total monitoring time serving as a time varying covariate. The same type of mixed model was used to evaluate activity levels during specific after-school sessions; however, session type was included as an additional fixed effect, and the monitoring time for the specific after-school session served as a time-varying covariate. Because the vigorous physical activity variable exhibited evidence of positive skewness, we used a generalized linear mixed model, using a Poisson distribution and the log link function. The analyses were performed with SAS PROC GLIMMIX, using the models described above. For all analyses, pairwise comparisons were evaluated for significance, using preplanned, single-degree-of-freedom contrasts. Significance was set at an alpha level of 0.05 .

\section{RESULTS}

Participant characteristics. A total of 140 students completed the after-school physical activity monitoring protocol on at least one occasion. The descriptive characteristics of the participants are shown in Table 1 . The final sample included slightly more boys than girls (56\% vs $44 \%)$ and students of diverse racial/ethnic and economic backgrounds (18\% African American; $11 \%$
Hispanic; 34\% eligible for free or reduced price lunch). Just more than $16 \%$ of the sample were classified as overweight, with a further $22.8 \%$ classified as at risk for overweight. In the analyses, overweight and at-risk-foroverweight students were combined into a single group.

After-school physical activity. During the course of the academic year, the 140 students completed a total of 610 accelerometer assessments. Thirty-eight (27.1\%) students completed all six assessments, 69 students (49.3\%) completed four or five assessments, 21 students $(15 \%)$ completed two or three assessments, and 12 students (8.6\%) completed one assessment. Four accelerometer assessments were excluded for inadequate wear time, providing a total of 606 valid accelerometer assessments. The average wear time for each accelerometer assessment was $93.8 \pm 29.5 \mathrm{~min}$.

Adjusted means for the after-school physical activity variables are displayed in Table 2. Students on average exhibited $42.6 \mathrm{~min}$ of SED, $40.8 \mathrm{~min}$ of LPA, $13.4 \mathrm{~min}$ of MPA, and 6.9 min of VPA. The average accumulation of MVPA was 20.3 min. Boys exhibited higher levels of MPA, VPA, and MVPA, and lower levels of SED and LPA, than girls; however, only the gender differences for LPA, VPA, and MVPA were significant at the 0.05 level. Overweight and at-risk-for-overweight students exhibited significantly less VPA than did nonoverweight students, but they had similar levels of LPA, MPA, and MVPA.

MVPA during specific sessions. During the course of the academic year, a total of 2375 after-school session types were coded and monitored via accelerometry. The number of valid accelerometer assessments, the relative frequency of each session, and the average duration for each

TABLE 3. Number of accelerometer assessments, relative frequency, and mean session duration.

\begin{tabular}{cccc}
\hline $\begin{array}{c}\text { After-School } \\
\text { Session }\end{array}$ & $\begin{array}{c}\text { Valid Accelerometer } \\
\text { Assessments }\end{array}$ & $\begin{array}{c}\text { Percentage of } \\
\text { Total Sessions }\end{array}$ & $\begin{array}{c}\text { Session } \\
\text { Duration } \\
(\mathbf{m i n})\end{array}$ \\
\hline $\begin{array}{c}\text { Free play } \\
\text { indoors }\end{array}$ & 183 & 7.7 & $26.7 \pm 17.2$ \\
$\begin{array}{c}\text { Organized PA } \\
\text { indoors }\end{array}$ & 270 & 11.4 & $26.3 \pm 15.9$ \\
$\begin{array}{c}\text { Free play } \\
\text { outdoors }\end{array}$ & 280 & 11.8 & $23.9 \pm 17.7$ \\
$\begin{array}{c}\text { Organized PA } \\
\text { outdoors }\end{array}$ & 63 & 2.7 & $28.1 \pm 13.6$ \\
$\begin{array}{c}\text { Snack time } \\
\text { Academic time }\end{array}$ & 615 & 25.9 & $14.4 \pm 5.6$ \\
\hline
\end{tabular}


TABLE 4. Adjusted means \pm SE for MVPA (min) in specific after-school sessions.

\begin{tabular}{|c|c|c|c|c|c|c|}
\hline \multirow[b]{2}{*}{ Group } & \multicolumn{6}{|c|}{ After-School Session } \\
\hline & Free Play Indoors & Organized PA Indoors & Free Play Outdoors & Organized PA Outdoors & Snack Time & Academic Time \\
\hline Total sample & $12.1 \pm 0.5^{\mathrm{a}}$ & $9.2 \pm 0.4^{b}$ & $12.7 \pm 0.4^{\mathrm{a}}$ & $5.7 \pm 0.7^{c}$ & $4.3 \pm 0.3^{c}$ & $1.0 \pm 0.2^{d}$ \\
\hline Boys & $14.4 \pm 0.6^{\mathrm{a} \star}$ & $10.5 \pm 0.5^{\mathrm{b} *}$ & $14.2 \pm 0.5^{\mathrm{a} *}$ & $6.7 \pm 1.1^{\mathrm{c}}$ & $4.6 \pm 0.4^{\mathrm{c}}$ & $0.9 \pm 0.3^{d}$ \\
\hline Girls & $9.8 \pm 0.6^{\mathrm{a}}$ & $7.9 \pm 0.5^{\mathrm{b}}$ & $11.1 \pm 0.6^{\mathrm{a}}$ & $4.7 \pm 1.0^{c}$ & $4.0 \pm 0.4^{\mathrm{C}}$ & $1.0 \pm 0.3^{d}$ \\
\hline Nonoverweight & $12.1 \pm 0.5^{\mathrm{a}}$ & $9.2 \pm 0.5^{b}$ & $12.7 \pm 0.5^{\mathrm{a}}$ & $7.2 \pm 1.0^{C} \ddagger$ & $4.4 \pm 0.3^{d}$ & $1.3 \pm 0.3^{\mathrm{e}}$ \\
\hline Overweight & $12.0 \pm 0.8^{\mathrm{a}}$ & $9.1 \pm 0.6^{b}$ & $12.6 \pm 0.6^{\mathrm{a}}$ & $4.2 \pm 1.0^{c}$ & $4.3 \pm 0.4^{\mathrm{C}}$ & $0.6 \pm 0.4^{d}$ \\
\hline
\end{tabular}

* Boys significantly different from girls, $P<0.05$.

$\ddagger$ Nonoverweight significantly different from overweight, $P<0.05$.

For each row, values not sharing a common superscript differ significantly, $P<0.05$.

session type are shown in Table 3. Organized sessions frequently included competitive games such as basketball, tag, kickball, and dodgeball. Free-play sessions frequently took place either in the gymnasium, where balls were provided, or outdoors, where children had access to playground equipment as well as balls. No unsupervised activity sessions were observed during the study.

Adjusted means for MVPA levels during each afterschool session type are reported in Table 4. MVPA levels were highest during free-play sessions regardless of whether they took place indoors or outdoors $(12.1-12.7 \mathrm{~min})$. Organized activity sessions conducted indoors provided significantly greater amounts of MVPA $(9.2 \mathrm{~min})$ than organized sessions conducted outdoors $(5.7 \mathrm{~min})$, but significantly less MVPA than that observed during either free-play session. Outdoor organized physical activity sessions, on average, provided little more MVPA than that observed during snack time. As expected, MVPA levels were significantly lower during academic time.

With the exception of academic time, boys were consistently more active than girls during each session type; however, only the gender differences for MVPA during indoor free play, outdoor free play, and organized activities indoors were significant at the 0.05 level. For most of the after-school sessions, overweight and at-riskfor-overweight students exhibited similar levels of MVPA than did nonoverweight students, with the notable exception of organized outdoor activities, during which overweight and at-risk-for-overweight students were significantly less active than their nonoverweight counterparts.

\section{DISCUSSION}

With opportunities for physical activity during the school day rapidly diminishing, after-school programs have become a key behavioral setting to promote physical activity and prevent overweight in children and adolescents. The present study used accelerometry to objectively quantify physical activity and sedentary behavior in children attending seven different after-school programs. Accelerometer assessments were completed throughout an entire school year, with three assessments conducted during the fall semester and three conducted during the spring semester. The results indicate that, on average, after-school programs provide approximately $20 \mathrm{~min}$ of MVPA daily.
Irrespective of session location (indoors vs outdoors), MVPA levels were significantly higher during free-play sessions than during organized or structured activity sessions. Boys were significantly more active than girls during indoor free play and organized outdoor activities, whereas overweight students were substantially less active than their nonoverweight counterparts during organized outdoor activities. These findings suggest that students accumulate significant amounts of MVPA while attending after-school programs. Additionally, session type, sex, and weight status seem to be important moderators of physical activity behavior during after-school time.

Although 20 min of MVPA is a significant amount of activity and fully accounts for one third of the daily 60-min physical activity requirement for youth, it is important to note that program participants spent the majority of their time performing sedentary and light-intensity activities. On average, students accumulated more than 80 min of sedentary to light activity, which far exceeded the 45-60 min normally allocated to mandatory nonactivity sessions such as snack time and academics. This observation suggests that program leaders can do more to promote physical activity and that the amount of MVPA provided by after-school programs can be increased. Given that the average duration of each activity-related session was less than $30 \mathrm{~min}$, and considering that, combined, the free play and organized physical activity sessions accounted for as little as one third of all monitored after-school sessions, a logical strategy to enhance MVPA levels would be to increase the frequency and duration of free play and organized physical activity sessions. However, considering the need for after-school program directors to maintain a balance between academic and physical activity programming, and the observed low levels of MVPA associated with organized activity sessions, a more practical approach may be to modify the existing organized activity sessions so that the percentage of time engaged in MVPA is increased. Research from physical education suggests that this goal can be achieved by a) enhancing program leaders' awareness of the importance of adequate physical activity, b) developing program leaders' administrative and instructional skills related to physical activity programming, and c) selecting developmentally appropriate physical activity experiences that emphasize enjoyable participation and enhancement of self-efficacy $(3,13)$. The results from one 
recent after-school intervention study suggest that such modifications are feasible and effective in promoting MVPA in the after-school setting (14).

In agreement with previously published studies evaluating activity levels in school-based settings, boys were significantly more active than girls $(25,26)$. On average, girls exhibited $40 \%$ less vigorous physical activity and $27 \%$ less MVPA than boys while attending an after-school program. Girls also demonstrated 22-32\% less MVPA than did boys during the free play and organized after-school activity sessions. Interestingly, moderate activity levels were similar for boys and girls, indicating that the bulk of the sex differential in MVPA was attributable to girls' lower participation in vigorous-intensity physical activity. This finding is consistent with those of Trost and colleagues (33), who observed a similar pattern of findings in a population-based sample of children and adolescents in grades 1-12. The factors responsible for girls' lower participation in vigorous physical activity are not well understood. It is possible that the lower levels of vigorous activity exhibited by girls during free-play situations may be a function of their preference for lower-intensity individual activities over more vigorous group or team activities or games (12). Alternatively, the lower levels of physical activity exhibited by girls relative to boys may be a function of differences in key mediators of physical activity behavior such as self-efficacy. In support of this concept, empirical studies have shown that the gender differences in physical activity are attributable, at least in part, to girls' lower levels of perceived competence, physical activity selfefficacy, enjoyment of physical activity, and perceived importance of sport and physical activity (34). Considering all of these potential explanations, it seems reasonable to suggest that after-school programs could reduce the sex difference in physical activity by providing activity choices that more appropriately cater to the needs and interests of girls and, in doing so, promote increased levels of selfefficacy and enjoyment of physical activity. In support of this assertion, a recently completed physical activity intervention study targeting adolescent girls reported a significant increase in physical activity after implementing a physical education curriculum that provided greater activity choices for girls and promoted positive self-efficacy and enjoyment of physical activity (24).

Previous objective monitoring studies have observed overweight children to be less active than their nonoverweight counterparts (31). In the present study, overweight and at-risk-for-overweight students exhibited similar amounts of light- and moderate-intensity physical activity as did nonoverweight students, but they had significantly lower amounts of vigorous physical activity. Moreover, the amount of MVPA during organized outdoor activities was approximately $40 \%$ lower in overweight and at-risk-foroverweight students compared with nonoverweight students. Although relative exercise intensity was not directly measured in this study, the lower levels of vigorous physical activity exhibited by overweight and at-risk-foroverweight children may be related to differences in aerobic fitness. Previous studies have shown overweight children to have significantly lower levels of maximal aerobic power than nonoverweight children when expressed relative to body mass or fat-free mass (38). Therefore, it is possible that overweight and at-risk-for-overweight students may be less inclined to participate in vigorous-intensity activities because, compared with nonoverweight students, these weightbearing activities are far more demanding for them. In addition, the large differential in activity levels during organized outdoor activities may be related to the common practice of playing competitive team sports and exclusion games during these sessions. Previous studies have reported overweight children to have inferior fundamental movement skills (20) and lower levels of perceived athletic competence (29) relative to nonoverweight children, and these factors may be responsible, in part, for the lower levels of MVPA observed among overweight students during organized activity sessions. Whatever the underlying cause, the lower levels of activity exhibited by overweight at-risk-for-overweight students during after-school time is a legitimate concern. Hence, gaining a better understanding of the activity preferences of overweight children attending after-school programs remains an important topic for future research.

An important finding of the present study was the significant difference in MVPA levels recorded during the free play and organized physical activity sessions. Depending on whether the sessions were conducted indoors or outdoors, MVPA levels during the organized physical activity sessions were, on average, 24-55\% lower than those recorded during free-play sessions. Although assessment of teaching practices was not a goal of the present investigation, it is reasonable to hypothesize that the lower levels of MVPA recorded during organized activity sessions may have been related to the limited physical activity instructional skills of the program leaders and the type of activities performed in this session. Specifically, the program leaders may have 1) devoted excessive amounts of time to administrative or "class" management functions at the expense of time for MVPA, and 2) selected activities or games in which students were frequently eliminated from game play (dodgeball) or were forced to wait in line for long periods of time (kickball). Although speculative, the somewhat higher levels of MVPA recorded during indoor organized activity sessions relative to outdoor organized sessions may have reflected the common practice of playing basketball in this setting. As noted earlier, research from physical education indicates that MVPA levels during organized activity sessions can be increased significantly through the provision of training programs to develop instructional skills related to physical activity programming $(3,13,24)$. It is also critically important that after-school programs adopt or develop evidence-based physical activity curricula that promote widespread participation in enjoyable, developmentally appropriate physical activity $(14,25)$. 
The significantly higher levels of MVPA recorded during free-play sessions serve as an important reminder that facilitating children's natural inclination to move and play may be one of the best strategies to promote physical activity in the after-school time period.

A major strength of this study was the rigorous assessment of physical activity behavior via accelerometry. In each of the seven after-school programs studied, activity levels were measured on six different occasions (a total of 42 monitoring days), with the assessments completed throughout an entire academic year. The accelerometer data were carefully screened for adequate wear time using widely endorsed decision rules (16), and care was taken to record the length of time participants attended the after-school program. To inform future intervention studies, activity levels during specific after-school sessions were assessed by carefully linking the accelerometer data to an observation system that recorded the different session types and their respective start and stop times. The inclusion of multiple after-school programs and the diversity of the schools and students participating in the study were also strengths.

Opposing these strengths were a number of limitations. First, although accelerometers provide valid estimates of the amount of time spent in different levels of physical activity intensity (e.g., minutes of MVPA), they do not provide information about the types of activities being performed or the physical and social environment in which physical activity is taking place. Therefore, additional descriptive studies employing direct observational systems or time-use diaries to capture contextual physical activity information are warranted. Additional limitations of accelerometers include the inability to capture the increased energy costs associated with walking and running uphill or on stairs, lifting and carrying objects, and performing static activities with significant upper-body movement (30). A second limitation was our use of a 30-s epoch. Although an epoch of $30 \mathrm{~s}$ is more likely to capture the intermittent physical activity patterns of children than a 1-min epoch, a shorter epoch $(\sim 15 \mathrm{~s})$ my have provided better resolution to detect brief bouts of vigorous-intensity physical activity (1).

\section{REFERENCES}

1. Baquet $G$, Stratton G, Van Praagh E, Berthoin S. Improving physical activity assessment in prepubertal children with highfrequency accelerometry monitoring: a methodological issue. Prev Med. 2007;44:143-7.

2. Burgeson CR, Wechsler H, Brener ND, Young JC, Spain CG. Physical education and activity: results from the School Health Policies and Programs Study 2000. J Sch Health. 2001;71:279-93.

3. Centers for Disease Control and Prevention. Guidelines for schools and community programs to promote lifelong physical activity among young people. MMWR. 1997;46(RR-6):1-36.

4. Centers for Disease Control and Prevention. Physical activity levels among children aged 9-13 years-United States, 2002. MMWR. 2003;52(33):785-8.

5. Centers for Disease Control and Prevention. Youth Risk Behavior Survey-United States, 2005. MMWR. 2006;55(SS-5): 23-6.
Therefore, the amount of vigorous physical activity performed by the after-school program participants in this study may have been underestimated. Third, because the study was strictly observational in nature, we did not have control over the frequency with which certain session types were offered. As a result, estimates of MVPA during some after-school sessions were based on a relatively small number of accelerometer assessments. This was particularly true for organized outdoor activity sessions, for which the estimate of MVPA was based on 63 accelerometer assessments. Consequently, the activity levels during organized activity sessions, and the associated comparisons between groups, should be interpreted with caution, and these require replication in future studies. Lastly, because the study only included after-school program participants who consented to participate in the study, we cannot rule out the possibility of selection bias (i.e., active or more athletic students were more likely to participate than low-active students). However, we believe that the study participants were representative of the students attending these programs, and it is noteworthy that our sample included significant numbers of overweight and minority students.

In summary, students accumulated approximately $20 \mathrm{~min}$ of MVPA while attending after-school programs. Activity levels were higher during free-play sessions than in organized or structured activity sessions. Importantly, sex and weight status were found to be moderators of after-school physical activity behavior, with boys exhibiting more vigorous and moderate to vigorous physical activity than girls, and overweight and at-risk-for-overweight students exhibiting less vigorous physical activity than nonoverweight students. After-school programs seem to be an important contributor to the physical activity of attending children. Nevertheless, ample room for improvement exists by extending or making better use of existing time devoted to physical activity.

Supported by the Cooperative State Research, Education, and Extension Service, U.S. Department of Agriculture, Award No. 200535215-15418.

6. Cox M, Schofield MJ, Greasley N, Kolt GS. Pedometer steps in primary school-aged children: a comparison of school-based and out-of-school activity. J Sci Med Sport. 2006;9:91-7.

7. Dale D, Corbin CB, Dale KS. Restricting opportunities to be active during school time: do children compensate by increasing physical activity levels after school? Res $Q$ Exerc Sport. 2000;71:240-8.

8. Dietz WH. Health consequences of obesity in youth: childhood predictors of adult disease. Pediatrics. 1998;101(3 Pt 2):518-25.

9. Ebbeling CB, Pawlak DB, Ludwig DS. Childhood obesity: publichealth crisis, common sense cure. Lancet. 2002;360(9331):473-82.

10. Flohr JA, Todd MK, Tudor-Locke C. Pedometer-assessed physical activity in young adolescents. Res Q Exerc Sport. 2006;77:309-15.

11. Freedson P, Pober D, Janz KF. Calibration of accelerometer output for children. Med Sci Sports Exerc. 2005;37(11 Suppl.): S523-30.

12. Hovell MF, Sallis JF, Kolody B, McKenzie TJ. Children's 
physical activity choices: a developmental analysis of gender, intensity levels, and time. Pediatr Exerc Sci. 1999;11:158-68.

13. Kahn EB, Ramsey LT, Brownson RC, et al. The effectiveness of interventions to increase physical activity. A systematic review. Am J Prev Med. 2002;22(4 Suppl.):73-107.

14. Kelder SD, Hoelscher M, Barroso CS, Walker JL, Cribb P, Hu S. The CATCH Kids Club: a pilot after-school study for improving elementary students' nutrition and physical activity. Public Health Nutr. 2005;8:133-40.

15. Kuczmarski RJ, Ogden CL, Grummer-Strawn LM, et al. CDC Growth Charts: United States. Adv Data. 2000;(314):1-27.

16. Masse LC, Fuemmeler BF, Anderson CB, et al. Accelerometer data reduction: a comparison of four reduction algorithms on select outcome variables. Med Sci Sports Exerc. 2005;37(11 Suppl.):S544-54.

17. McKenzie TL, Marshall SJ, Sallis JF, Conway TL. Leisure-time physical activity in school environments: an observational study using SOPLAY. Prev Med. 2000;30:70-7.

18. National Association for Sport and Physical Education and American Heart Association. 2006 Shape of the Nation Report: Status of Physical Education in the USA. Reston (VA): National Association for Sport and Physical Education; 2006.

19. Ogden CL, Carroll MD, Curtin LR, McDowell MA, Tabak CJ, Flegal KM. Prevalence of overweight and obesity in the United States, 1999-2004. JAMA. 2006;295:1549-55.

20. Okely AD, Booth ML, Chey T. Relationships between body composition and fundamental movement skills among children and adolescents. Res Q Exerc Sport. 2004;75:238-47.

21. Pate RR, Freedson PS, Sallis JF, et al. Compliance with physical activity guidelines: prevalence in a population of children and youth. Ann Epidemiol. 2002;12:303-8.

22. Pate RR, Stevens J, Pratt C, et al. Objectively measured physical activity in sixth-grade girls. Arch Pediatr Adolesc Med. 2006;160: 1262-8.

23. Pate RR, Trost SG, Mullis R, Sallis JF, Wechsler H, Brown DR. Community interventions to promote proper nutrition and physical activity among youth. Prev Med. 2000;31:S138-49.

24. Pate RR, Ward DS, Saunders RP, Felton G, Dishman RK, Dowda M. Promotion of physical activity among high-school girls: a randomized controlled trial. Am J Public Health. 2005;95: $1582-7$.

25. Ridgers ND, Stratton G, Fairclough SJ. Physical activity levels of children during school playtime. Sports Med. 2006;36:359-71.

26. Sarkin JA, McKenzie TL, Sallis JF. Gender differences in physical activity during fifth grade physical education and recess periods. J Teach Phys Educ. 1997;17:99-106.
27. Sherar LB, Esliger DW, Baxter-Jones ADG, Tremblay MS. Age and gender differences in youth physical activity: does physical activity maturity matter? Med Sci Sports Exerc. 2007; 39(5):830-5

28. Steinbeck KS. The importance of physical activity in the prevention of overweight and obesity in childhood: a review and an opinion. Obes Rev. 2001;2:117-30.

29. Taylor WC, Sallis JF, Dowda M, Freedson PS, Eason K, Pate RR. Activity patterns and correlates among youth: differences by weight status. Pediatr Exerc Sci. 2002;14:418-31.

30. Trost SG. Objective measurement of physical activity in youth: current issues, future directions. Exerc Sport Sci Rev. 2001; 29:32-6.

31. Trost SG, Kerr LM, Ward DS, Pate RR. Physical activity and determinants of physical activity in obese and non-obese children. Int J Obes Relat Metab Disord. 2001;25:822-9.

32. Trost SG, McIver KL, Pate RR. Conducting accelerometer-based activity assessments in field-based research. Med Sci Sports Exerc. 2005;37(11 Suppl.):S531-43.

33. Trost SG, Pate RR, Sallis JF, et al. Age and gender differences in objectively measured physical activity in youth. Med Sci Sports Exerc. 2002;34(2):350-5.

34. Trost SG, Ward DS. Factors related to girls' participation in physical activity. In: Ransdell LB, Petlichkoff L, editors. Ensuring the Health of Active and Athletic Girls and Women. Reston (VA): National Association for Girls and Women in Sport; 2005. p. 3-28.

35. Trost SG, Ward DS, Moorehead SM, Watson PD, Riner W, Burke JR. Validity of the computer science and applications (CSA) activity monitor in children. Med Sci Sports Exerc. 1998;30(4): 629-33.

36. Tudor-Locke C, Lee SM, Morgan CF, Beighle A, Pangrazi RP. Children's pedometer determined physical activity during the segmented school day. Med Sci Sports Exerc. 2006;38: 1732-8.

37. Vandell DL, Pierce KM, Dadisman K. Out-of-school settings as a developmental context for children and youth. Adv Child Dev Behav. 2005;33:43-77.

38. Ward DS, Evans R. Physical activity, aerobic fitness, and obesity in children. Med Exerc Nutr Health. 1995;4:3-16.

39. Whitaker RC, Wright JA, Pepe MS, Seidel KD, Dietz WH. Predicting obesity in young adulthood from childhood and parental obesity. N Engl J Med. 1997;337(13):869-73.

40. Wickel EE, Eisenmann JC. Contribution of youth sport to total daily physical activity among 6- to 12-yr-old boys. Med Sci Sports Exerc. 2007;39(9):1493-500. 